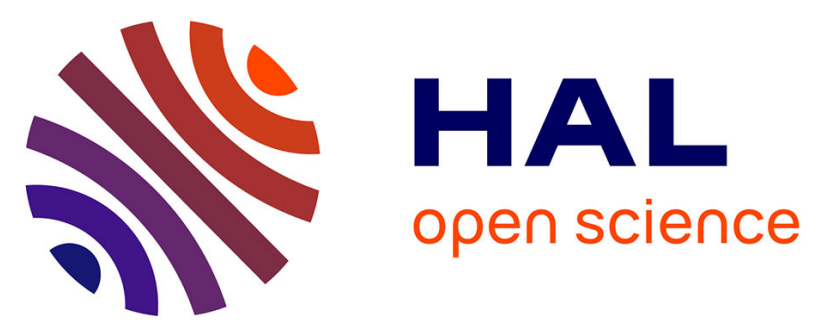

\title{
Structure and molecular dynamics of multilayered polycarbonate/polystyrene films.
}

Malgorzata Walczak, Wlodzimierz Ciesielski, Andrzej Galeski, Marek

Potrzebowski, Gilles Regnier, Anne Hiltner, Eric Baer

\section{To cite this version:}

Malgorzata Walczak, Wlodzimierz Ciesielski, Andrzej Galeski, Marek Potrzebowski, Gilles Regnier, et al.. Structure and molecular dynamics of multilayered polycarbonate/polystyrene films.. Journal of Applied Polymer Science, 2012, 125, pp.4347-4357. 10.1002/app.36567 . hal-00793173

\section{HAL Id: hal-00793173 \\ https://hal.science/hal-00793173}

Submitted on 25 Feb 2013

HAL is a multi-disciplinary open access archive for the deposit and dissemination of scientific research documents, whether they are published or not. The documents may come from teaching and research institutions in France or abroad, or from public or private research centers.
L'archive ouverte pluridisciplinaire HAL, est destinée au dépôt et à la diffusion de documents scientifiques de niveau recherche, publiés ou non, émanant des établissements d'enseignement et de recherche français ou étrangers, des laboratoires publics ou privés. 


\title{
Structure and Molecular Dynamics of Multilayered Polycarbonate/Polystyrene Films
}

\author{
M. Walczak, ${ }^{1}$ W. Ciesielski, ${ }^{1}$ A. Galeski, ${ }^{1}$ M. J. Potrzebowski, ${ }^{1}$ G. Regnier, ${ }^{2}$ A. Hiltner, ${ }^{3}$ E. Baer ${ }^{3}$ \\ ${ }^{1}$ Department of Polymer Physics, Centre of Molecular and Macromolecular Studies, Polish Academy of Science, \\ 90363 Lodz, Poland \\ ${ }^{2}$ Procédés et Ingénierie en Mécanique et Matériaux (PIMM), Arts et Metiers ParisTech, CNRS, 75013 Paris, France \\ ${ }^{3}$ Department of Macromolecular Science and Engineering, Case Western Reserve University, Cleveland, Ohio 44-106
}

\begin{abstract}
Multilayered film polycarbonate/polystyrene (PC/PS) comprising 257 layers with total thickness $125 \mu \mathrm{m}$ was made by coextrusion process. The nominal thickness of PC layers was $680 \mathrm{~nm}$, and the nominal thickness of PS layers was $290 \mathrm{~nm}$. Additionally, the control samples of PC and PS with the thickness of $125 \mu \mathrm{m}$ were coextruded in the same way. There was reasonably good correlation between the PC and PS layers real thickness as measured by AFM and the estimated thickness determined from the processing parameters. Significant shift of glass transition temperature is observed in multilayer film: for PS component toward higher temperature while PC still being glassy and for PC toward lower temperature while PS being in rubbery phase. To investigate the ampli-
\end{abstract}

tude and geometry of fast segmental motions, the LG-CP NMR technique under fast magic-angle spinning was used. 2D ${ }^{13} \mathrm{C}-{ }^{1} \mathrm{H}$ LG-CP spectra of PC, PS, and PC/PS $70 / 30$ were recorded at various temperatures. Cross sections of aromatic carbons spectra show us the influence of PC on PS and vice versa. It gives us also the information about PS and PC segmental motion as a function of temperature: above the glass transition temperature of PS, the PC component of a multilayer film, although still being in glassy state, becomes more flexible. (c) 2012 Wiley Periodicals, Inc. J Appl Polym Sci 000: 000-000, 2012

Key words: interface; polystyrene; polycarbonate; molecular dynamics

\section{INTRODUCTION}

Wide range of polymer properties result from a great variety of chemical and supermolecular structures complexity that can be relatively easy modified by tuning conditions of phase transitions, blending, or compounding.

Two different phases or two dissimilar polymers while being in contact interact with each other and form an interface. The interaction occurs at the surfaces of substances involved, that is at their interfaces. The interaction between polymers is usually described by interfacial tension or energy. Interfacial tension is arising at an interface from the imbalance of forces between molecules at an interface, molecules at the interface experience an imbalance of forces. This leads to accumulation of free energy at the interface. The main forces involved in interfacial tension are adhesive forces between one phase or polymer and another phase or polymer.

The interface is not infinitely thin; the depth of interaction depends on a physico-chemical similarity

Correspondence to: A. Galeski (andgal@cbmm.lodz.pl). of a pair of polymers, also the thickness of the interfacial layer.

Polymer blends are systems with highly developed interfaces. However, when two immiscible polymers are blended the interfaces are not anymore flat. That is because usually polymer blend morphology resembles dispersion with micrometer sized inclusions of a minor component. In such blends, surface tension exerts a pressure on a spherical drop that is higher if the drop is smaller according to the formula:

$$
P=-\gamma_{A} / 2 r
$$

where $r$ is the radius of a drop. For small micrometer and nanometer drops, the pressure can reach significant values. In addition, a difference in thermal expansibilities of polymers may produce extra component of pressure. Flat interfaces are then betterdefined objects for studying interfaces between two polymers.

Thickness of the interface layer depends very much on polymers being in contact. There are reports indicating that the interface layer between polymers can be as thick as $10 \mathrm{~nm}$, as in the case of poly(methyl methacrylate)/polycarbonate. ${ }^{1}$ A bilayer film will have a single interface layer; the volume of interface layer is, however, a small fraction of the entire volume of a bilayer film. Multilayer films that can be produced by forced assembly through layer- 


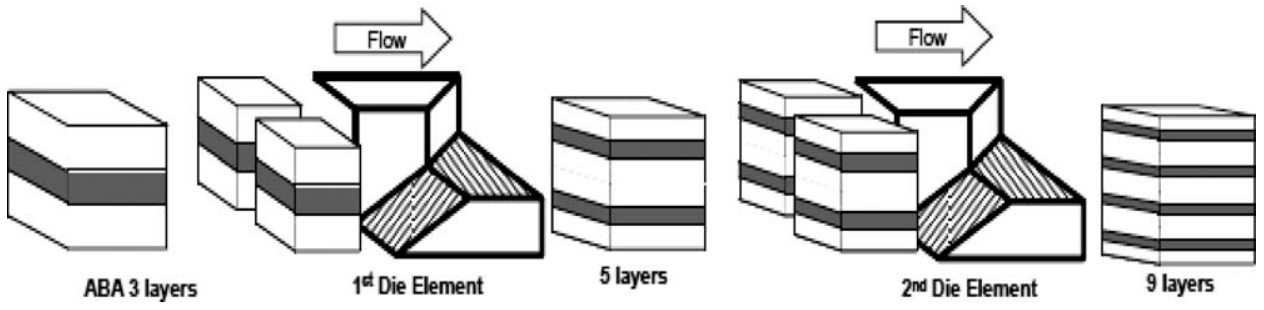

Figure 1 Layer-multiplying coextrusion for forced-assembly of polymer nanolayers.

multiplying coextrusion ${ }^{2-4}$ contain multifold larger amount of interfaces because for $2^{n}$ layers there are $2^{n}-1$ interfacial layers.

The aim of these studies was to find a way of sensing and to elucidate the influence of one polymer on the other at the interface. We have selected the pair of polymers: polycarbonate/polystyrene (PC/PS). Solid state nuclear magnetic resonance (SSNMR) was chosen as the main tool for investigation of interactions at interfaces. ${ }^{5,6}$ SSNMR is an analytical technique that systematically extends the repertoire of novel approaches, allowing better understanding of the nature of polymers. This field was exhaustively reviewed, and a number of articles and books have been published. ${ }^{7-10}$ Significant contributions regarding SSNMR studies of organic polymers come from Spiess group. ${ }^{11,12}$

Important source of information about the structure and dynamics of polymers are dipolar-recoupling experiments, which are well suited for measuring motional averaging at multiple sites simultaneously in biomolecules and synthetic polymers. ${ }^{13-15}$ In twodimensional (2D) approach separated local field sequences can reintroduce dipolar anisotropic interactions and correlate them to isotropic chemical shifts. The Lee-Goldburg cross-polarization (LG CP) ${ }^{16,17}$ and polarization inversion spin exchange at the magic angle (PISEMA) ${ }^{18}$ pulse sequences were recently used to correlate the motionally average anisotropic dipolar interactions with high-resolution chemical shift dimensions during MAS in 2D approach.

We expect to gain the information about how far is the interaction between PS and PC reaching, how it changes with temperature when the mobility of PS or PC macromolecules is activated and what is the influence of the other component. Finally, we would expect to learn how the interactions at interfaces influence the overall properties of multilayered film.

\section{MATERIALS AND METHODS}

\section{Preparation of films}

Multilayered film (PC/PS) with 257 layers was extruded from melt on a laboratory scale coextrusion line at Case Western Reserve University that incorporates layer-multiplying technology. ${ }^{19}$ The sche- matic drawing of layer-multiplying coextrusion in Figure 1 shows how a series of $n$ multiplying elements combines two dissimilar polymers as $2(n+1)$ +1 alternating layers. ${ }^{20,21}$ After the polymer melts, materials are combined in the ABA feed block, the melt stream flows through a series of layer-multiplying die elements. Each element splits the melt vertically, spreads it horizontally, and finally recombines it with twice the number of layers. Finally, the melt is spread in a film die to reduce further the layer thickness.

The total film thickness was $125 \mu \mathrm{m}$. The weight composition of multilayered film was $70 / 30$, where the thickness of PC was $680 \mathrm{~nm}$, and the thickness of PS was $290 \mathrm{~nm}$. The temperature of coextrusion was $270^{\circ} \mathrm{C}$. Additionally, the control samples of PC and PS with the thickness of $125 \mu \mathrm{m}$ were coextruded in the same way.

The polycarbonate was Dow Calibre 200-15 with bulk density $1.20 \mathrm{~g} / \mathrm{cm}^{3}$ according to ASTM D792 and melt flow index of $15 \mathrm{~g} / 10 \mathrm{~min}$ according to ASTM D1238. The polystyrene was Dow STYRON 685D with bulk density $1.04 \mathrm{~g} / \mathrm{cm}^{3}$ according to ASTM D 792 and melt flow index of $1.5 \mathrm{~g} / 10 \mathrm{~min}$ according to ASTM D1238.

\section{AFM study}

The thickness of individual polycarbonate and polystyrene layers was measured by atomic force microscopy (AFM). The film was embedded in epoxy resin (Araldite Resin Mollenhauer Mixture) and cured for $24 \mathrm{~h}$ at $60^{\circ} \mathrm{C}$. Cross-sections were microtomed perpendicular to the plane of the film by glass knife and observed. The AFM images were obtained in air with a commercial multimode scanning probe microscope (Nanoscope IIIa, Digital Instruments,) operated in the tapping mode. Measurements were performed at ambient conditions using rectangular type Si probes with a spring constant of $42 \mathrm{~N} / \mathrm{m}$ and resonance frequencies in the $264-311 \mathrm{kHz}$ range. The tip radius was $10 \mathrm{~nm}$.

\section{DSC study}

Thermal properties of the multilayered films were studied by differential scanning calorimetry on a TA 

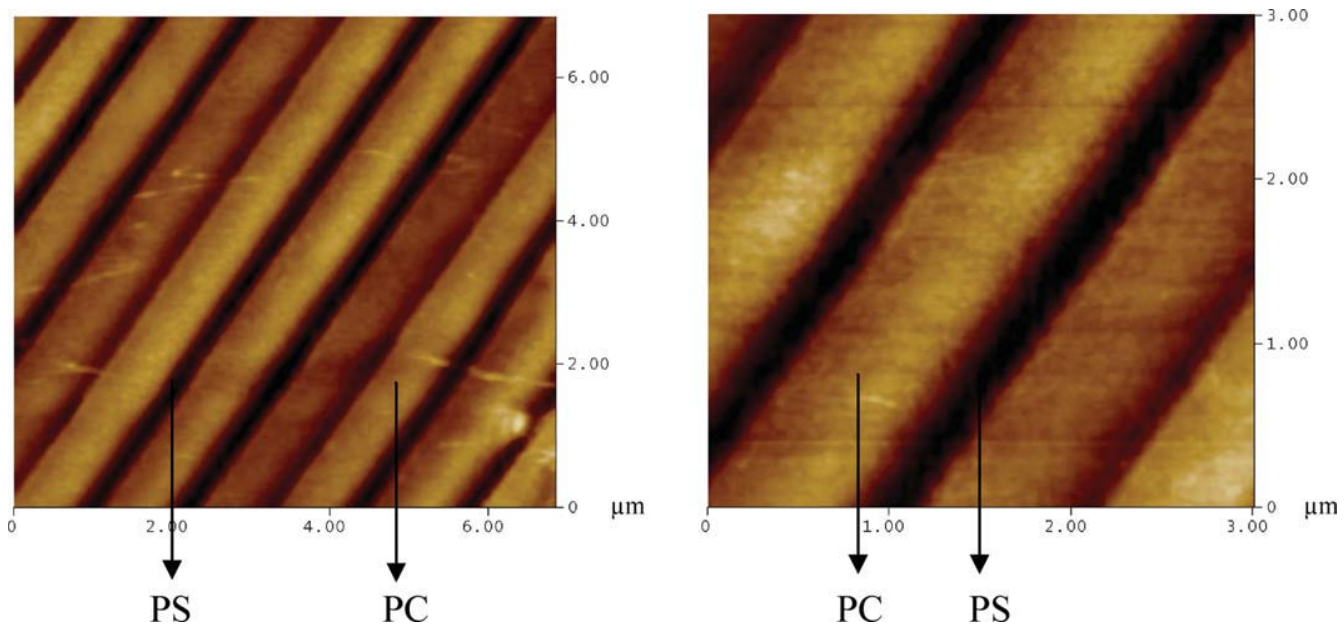

Figure 2 AFM images of PC/PS 70/30 $125 \mu \mathrm{m}$ thick multilayer film (left image: low magnification image; right image: higher magnification image). [Color figure can be viewed in the online issue, which is available at wileyonlinelibrary.com.]

Instruments Qseries 1000 apparatus. The films with a weight around $10 \mathrm{mg}$ were placed inside aluminum pan and heated with a rate of $30^{\circ} \mathrm{C} / \mathrm{min}$ from 20 to $180^{\circ} \mathrm{C}$.

\section{NMR study}

The solid-state magic angle spinning (MAS) experiments were performed on a BRUKER Avance III 400 spectrometer at $100.613 \mathrm{MHz}$ frequency for ${ }^{13} \mathrm{C}$, equipped with a MAS probe head using $4 \mathrm{~mm} \mathrm{ZrO}_{2}$ rotors. A sample of glycine was used for setting the Hartmann-Hahn condition, and glycine was used as a secondary chemical shift reference $\delta=176.04 \mathrm{ppm}$ from external TMS. ${ }^{22}$ The conventional spectra were recorded with a proton $90^{\circ}$ pulse length of $4 \mu \mathrm{s}$ and a contact time of $2 \mathrm{~ms}$. The repetition delay was $6 \mathrm{~s}$, and the spectra width was $25 \mathrm{kHz}$. The FIDs were accumulated with a time domain size of $2 \mathrm{~K}$ data points. The RAMP shape pulse ${ }^{23}$ was used during the cross-polarization and spinal TPPM decoupling. ${ }^{24}$ The cross-polarization efficiency was measured with contact times between $10 \mu$ and $12 \mathrm{~ms}$. The spectral data were processed using the TOPSPIN program. ${ }^{25}$

For the LG-CP period, the ${ }^{1} \mathrm{H}$ effective field strength was $50 \mathrm{kHz}$ in all experiments, and the ${ }^{13} \mathrm{C}$ spin-lock field strengths was adjusted to the firstorder sideband condition $\omega_{13 C}=\omega_{1 \text { Heff }}-\omega_{r}$. Spinning speed was $13 \mathrm{kHz}$ and was regulated to \pm 3 $\mathrm{Hz}$ by a pneumatic control unit. Recycle delays varied from 1.5 to $4 \mathrm{~s}$. The 2D LG-CP experiments incremented the LGCP contact time at a step of $16.28 \mu \mathrm{s}$. At a spinning speed of $13 \mathrm{kHz}$, the dwell time for the evolution period was thus $19.23 \mu$ s. The maximum $t_{1}$ evolution time was typically about 1 ms. Only cosine-modulated data were collected.
Thus, a real Fourier transformation was performed on the $t_{1}$ data, yielding spectra with a symmetrized $\omega_{1}$ dimension and showing the dipolar splittings. Since the $t_{1}$ time signal increases with increasing LG-CP contact time, the $\omega_{1}$ dimension was processed using the baseline correction mode "qfil" in the TOPSPIN software. This subtracts a constant intensity from the time signals before Fourier transformation and yields spectra free of a dominant zero-frequency peak giving ${ }^{1} \mathrm{H}-{ }^{13} \mathrm{C}$ doublet.

\section{RESULTS AND DISCUSSION}

\section{Layer characterization}

Cross sections of coextruded films with alternating layers of PC and PS are shown in Figure 2. Dark PS layers were thinner than light PC layers. Good layer uniformity was clearly evident in the low-resolution images. For higher resolution images, the PC layers were about $680 \mathrm{~nm}$ thick and PS layers about 290 nm thick (Table I). There was reasonably good correlation between PC and PS layers thickness measured from the AFM images and the estimated thickness determined from the processing parameters.

TABLE I

PC and PS Layers Thickness Measured from the AFM Images and the Estimated Thickness Determined from the Processing Parameters

\begin{tabular}{llllll}
\hline & \multicolumn{2}{c}{$\begin{array}{c}\text { Calculated } \\
\text { layers } \\
\text { thickness (nm) }\end{array}$} & & \multicolumn{2}{c}{$\begin{array}{c}\text { Measured by } \\
\text { AFM layers } \\
\text { thickness (nm) }\end{array}$} \\
\cline { 2 - 3 } $\begin{array}{c}\text { Multilayered } \\
\text { film PC/PS }\end{array}$ & PC & PS & & PC & PS \\
\hline $70 / 30$ & 680 & 290 & & $\approx 685$ & $\approx 298$ \\
\hline
\end{tabular}


TABLE II

Shifts in Glass Transition Temperatures of PC and PS in Multilayered Film

\begin{tabular}{lcc}
\hline \multirow{2}{*}{ Material } & \multicolumn{2}{c}{ Q1000, ramp $30^{\circ} \mathrm{C} / \mathrm{min}$} \\
\cline { 2 - 3 } & $T_{g}$ of PS $\left({ }^{\circ} \mathrm{C}\right)$ & $T_{g}$ of PC $\left({ }^{\circ} \mathrm{C}\right)$ \\
\hline PC control, $125 \mu \mathrm{m}$ & - & 154.08 \\
PC $/$ PS, 70/30, $125 \mu \mathrm{m}$ & 109.09 & 151.71 \\
PS control, $125 \mu \mathrm{m}$ & 107.62 & - \\
\hline
\end{tabular}

\section{Thermal properties}

Heating thermograms showed the glass transition for PS in the range of $107.6^{\circ} \mathrm{C}$, and for PC we could observe $T_{g}$ at $154.1^{\circ} \mathrm{C}$ for the heating rate $30^{\circ} \mathrm{C} / \mathrm{min}$. For multilayer film of PC/PS, 70/30 the glass transition temperature is at 109.1 and $151.7^{\circ} \mathrm{C}$ for PS and PC component, respectively. Significant shifts of glass transition temperature are observed in multilayer films: for PS component toward higher temperature while PC still being glassy and for PC toward lower temperature while PS being in rubbery phase. The glass transition temperature shifts suggest rather strong interactions between PS and PC components (Table II).

\section{${ }^{13} \mathrm{C}$ CP/MAS NMR study of PC, PS, and PC/PS} film

Pieces of films for all polymer systems were rolled and inserted into the $4 \mathrm{~mm}$ zirconium rotors. Figure 3 displays ${ }^{13} \mathrm{C} \mathrm{CP} /$ MAS NMR spectra of PC and PS films recorded at room temperature with the spinning rate $8 \mathrm{kHz}$ [Fig. 3(a,b), respectively]. The structure assignment is given in Figures. The numbering system for PC and PS polymers is shown as inset in
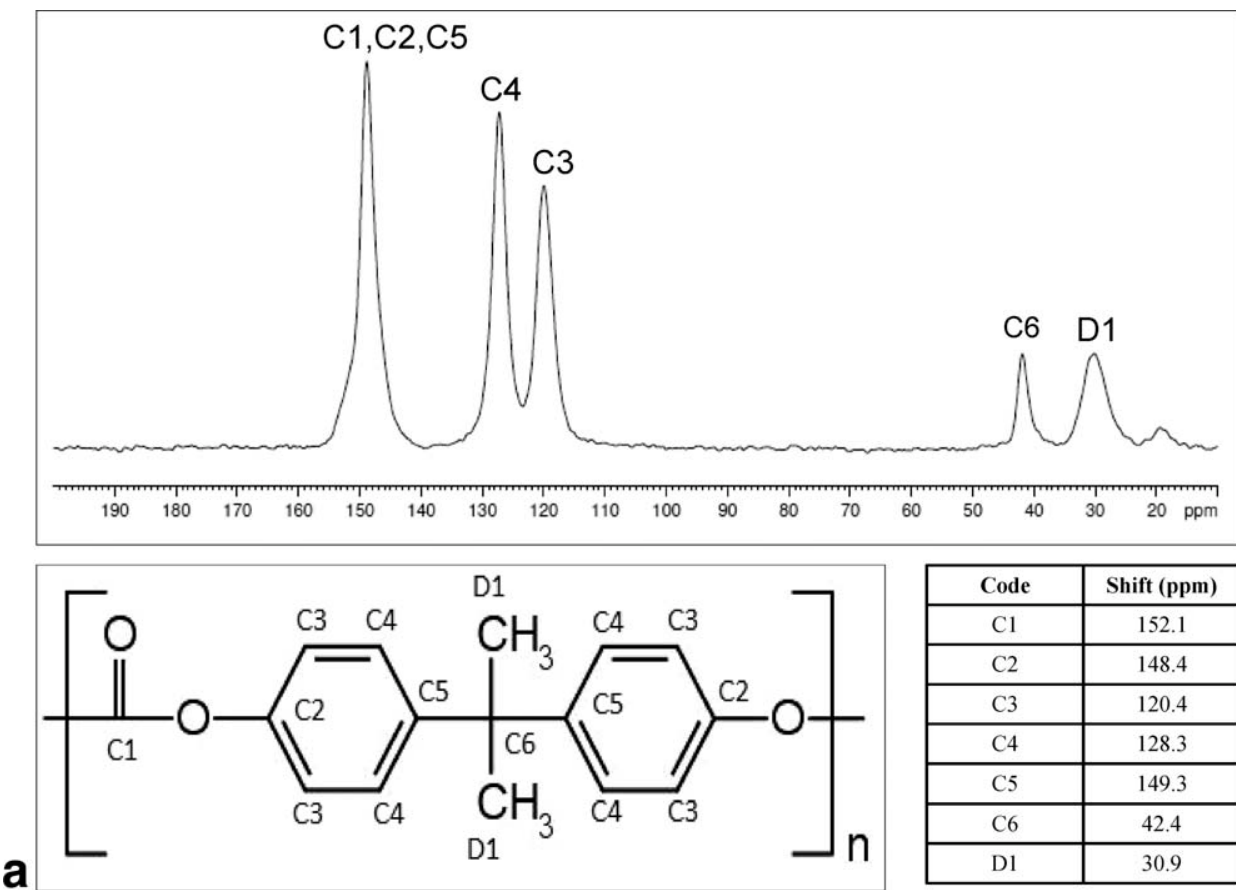

\begin{tabular}{|c|c|}
\hline Code & Shift (ppm) \\
\hline C1 & 152.1 \\
\hline C2 & 148.4 \\
\hline C3 & 120.4 \\
\hline C4 & 128.3 \\
\hline C5 & 149.3 \\
\hline C6 & 42.4 \\
\hline D1 & 30.9 \\
\hline
\end{tabular}
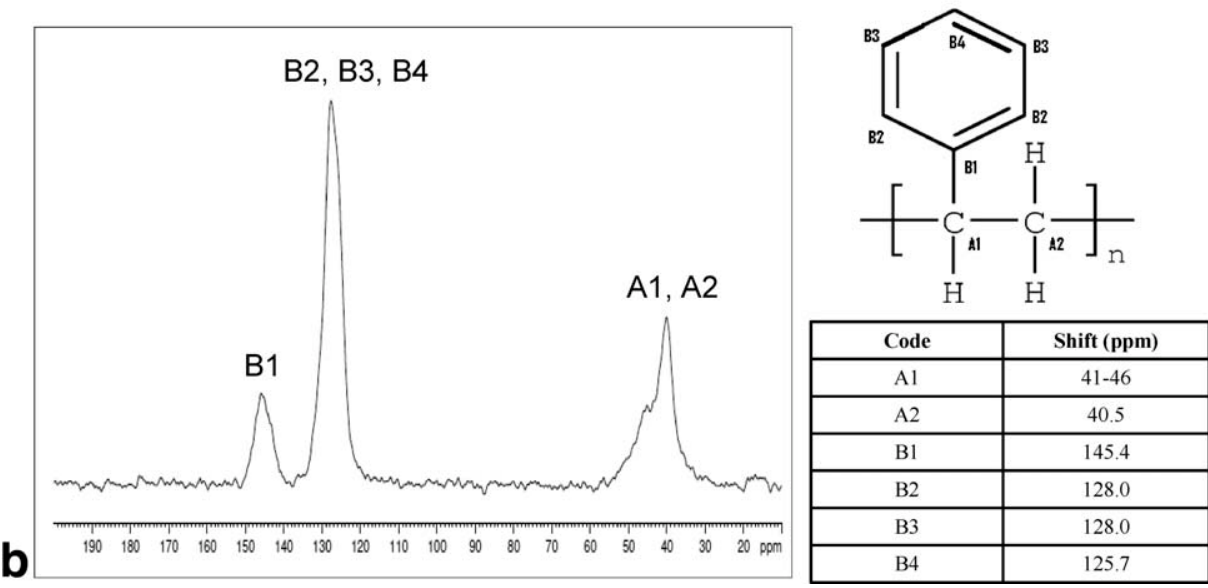

Figure 3 (a) ${ }^{13} \mathrm{C} \mathrm{CP} /$ MAS NMR spectra of PC. (b) ${ }^{13} \mathrm{C} \mathrm{CP} / \mathrm{MAS}$ NMR spectra of PS. 


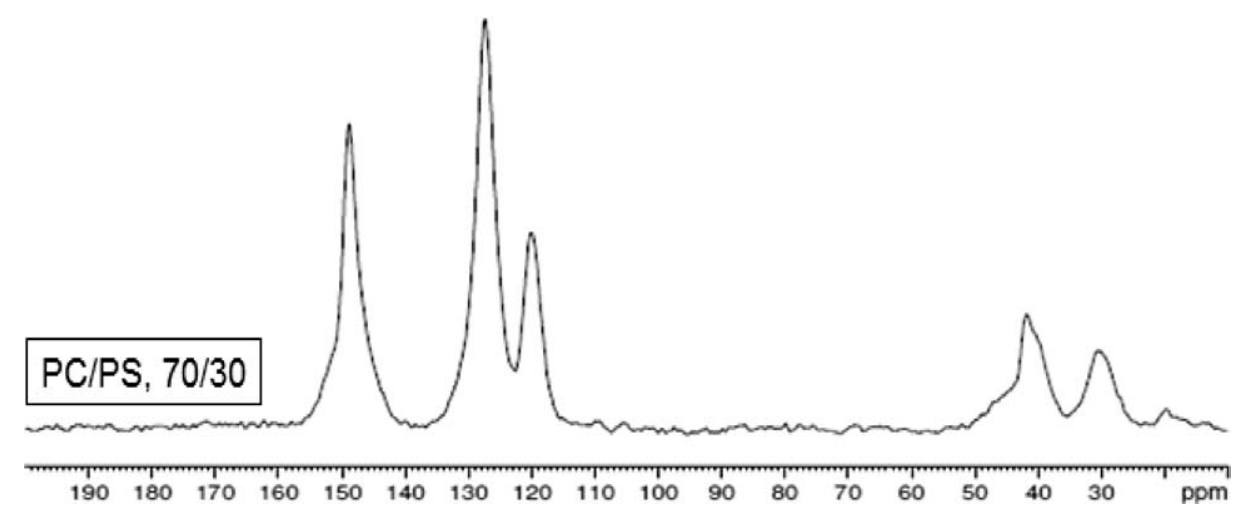

Figure $4{ }^{13} \mathrm{C} \mathrm{CP} / \mathrm{MAS}$ NMR spectra of PC/PS 70/30 $125 \mu \mathrm{m}$ thick film.

the top of spectra. From inspection of data, it is apparent that signals for PC sample representing C1, $\mathrm{C} 2$, and $\mathrm{C} 5$ carbons are overlapped and observed as broadened peak at average chemical shift at about $150 \mathrm{ppm}$. Resonances of C3 and C4 carbons are well separated and found at $\delta=120.4 \mathrm{ppm}$ and $\delta=128.3$ $\mathrm{ppm}$. Aliphatic part of PC is represented by two sets of NMR signals, quaternary carbon C 6 at $\delta=42.4$ and methyl group carbons D1 at $\delta=30.9 \mathrm{ppm}$.

${ }^{13} \mathrm{C} \mathrm{CP} /$ MAS spectrum of PS film shown in Figure $3(b)$ is represented by three sets of signals; quaternary carbons B1 at $\delta=145.4 \mathrm{ppm}$, overlapped aromatic B2, $\mathrm{B} 3$, and $\mathrm{B} 4$ at $\delta=126-128 \mathrm{ppm}$ and broadened aliphatic A1 and A2 signals at 40-46 ppm. From preliminary study of pure polymer films, it is evident that some NMR signals from both samples are in very similar regions. This observation is confirmed by NMR investigation of coextruded films in Figure 4.

Figure 4 shows ${ }^{13} \mathrm{C} \mathrm{CP} /$ MAS NMR spectrum of PC/PS $70: 30$ film recorded under exactly the same conditions as those presented in Figure 3. As predicted some resonances representative for PC and PS polymer films are overlapped. For instance, signal centered at $\delta=128 \mathrm{ppm}$ represents $\mathrm{C} 4$ carbons of PC and B2, B3, and B4 carbons of PS form a single broadened peak. Signal at $\delta=120.4 \mathrm{ppm}$ represents exclusively carbon C3 of PC. Thus, by simple integration of these two signals we can conclude the proportion of PC and PS components in the films

a)
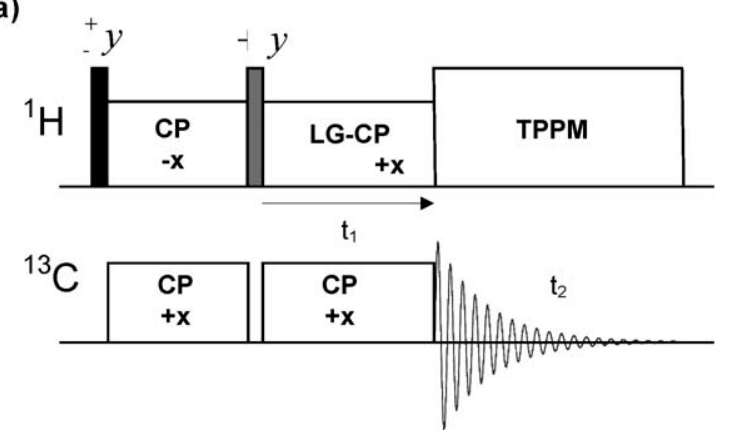

keeping in mind that region of 128 ppm represents two carbons of PC and five carbons of PS while the region around $120.4 \mathrm{ppm}$ is only for PC.

\section{Solid state NMR study of molecular dynamics for} PC, PS, and PC/PS film

In our project for analysis of the effect of molecular motion on the line shape of the dipolar spectra, we have carried out sensitivity-enhanced LG-CP measurement, employing PILGRIM pulse sequence (phase-inverted LG recoupling under MAS) shown in Figure 5(a). ${ }^{26}$ Compared to standard LG CP [Fig. $5(b)]$ the theoretical sensitivity enhancement factor for PILGRIM is equal (2), in practice less.

Figure 6(a) shows contour plot of 2D spectrum for PC film recorded with spinning rate $13 \mathrm{kHz}$ at ambient temperature. The ${ }^{1} \mathrm{H}$ effective field strength, $\omega_{1 \text { Heff, }}$ was matched to the ${ }^{13} \mathrm{C}$ spin-lock field strength $\delta_{13 C}$, by $\omega_{1 \text { Heff }}-\omega_{13 C}=\omega_{r}(-1$ condition $)$. The LG CP contact time was incremented asynchronously with rotation to yield the heteronuclear dipolar dimension of the $2 \mathrm{D}$ experiment. The ${ }^{13} \mathrm{C}$-spin isotropic chemical shift was detected in the second dimension of the experiment. Similar experiment, under exactly the same conditions as for sample PC was carried out for PS as well PC/PS film.

For LG-CP experiment, the line shapes resemble a Pake pattern [Fig. 6(b)] without the outer two

b)
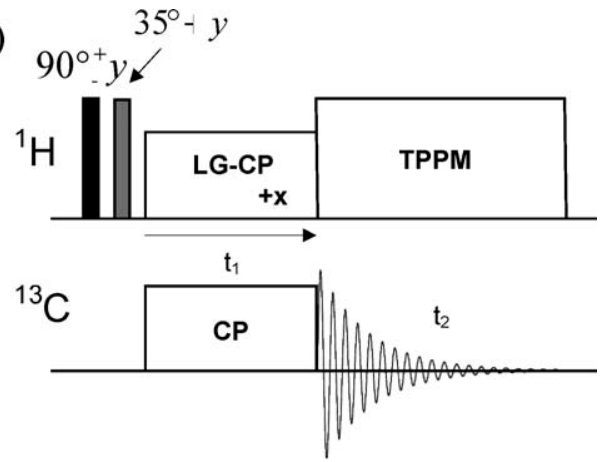

Figure 5 Pulse sequences: (a) 2D PILGRIM and (b) 2D LG-CP MAS. 

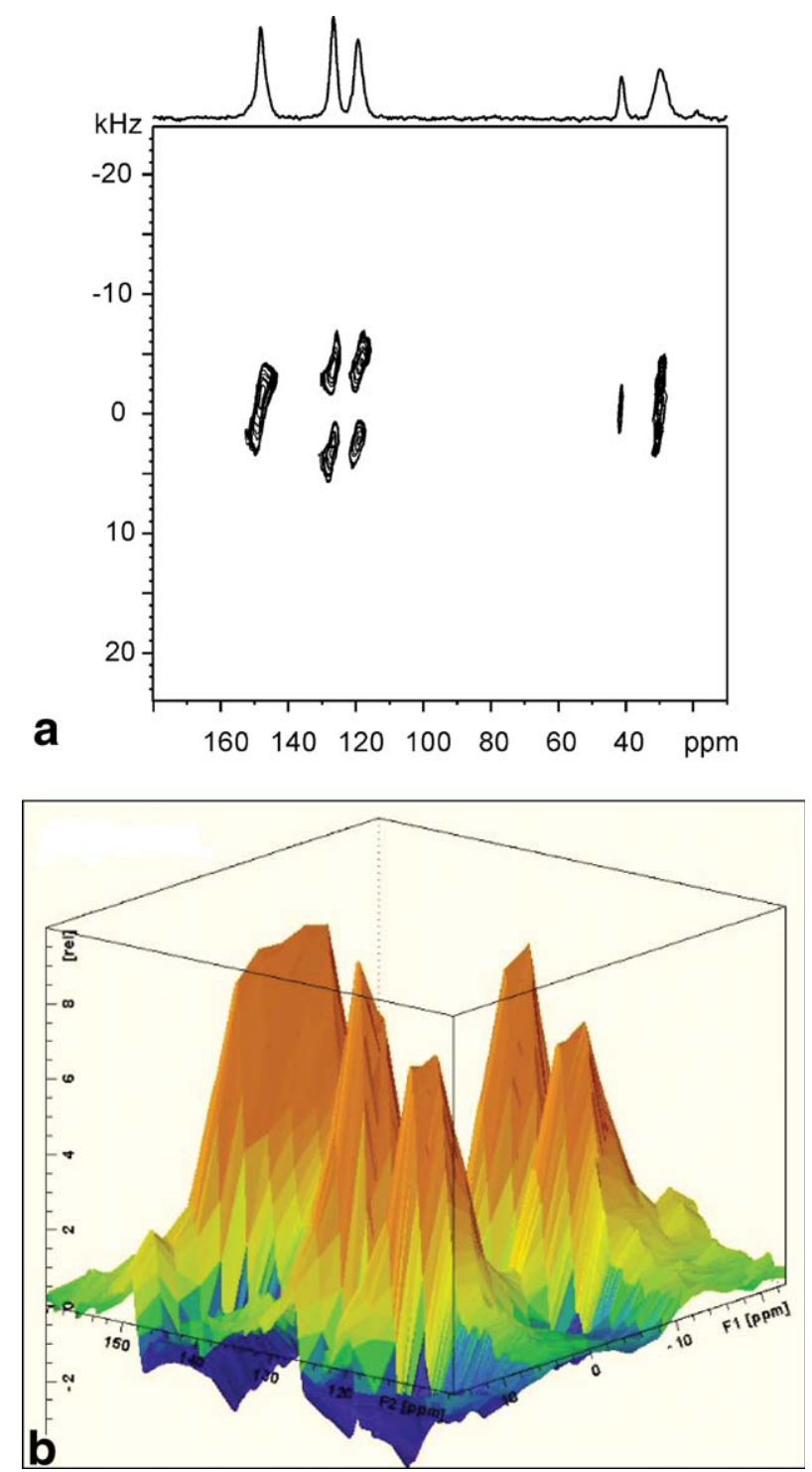

Figure 6 (a) Contour plot of 2D spectrum for PC film. (b) 2D LG-CP stack plot for PC film. Only aromatic part of spectrum is shown. [Color figure can be viewed in the online issue, which is available at wileyonlinelibrary.com.]

"shoulders" with splitting between singularities equal to 0.58 times $\left(\cos \Theta_{m}\right.$ ) of dipolar coupling $\delta$ where $\delta$ is expressed by equation:

$$
\delta=-\frac{\mu_{0} \hbar^{2}}{4 \pi} \frac{\gamma_{i} \gamma_{j}}{r_{i j}^{3}}
$$

For ${ }^{13} \mathrm{C}-{ }^{1} \mathrm{H} r_{i j}$ distance equal to $1.09 \AA, \delta$ for rigidlimit is $22.7 \mathrm{kHz}$. For static phenyl rings with $\eta=0$, the splitting is $12.9 \mathrm{kHz}$. Asymmetry $\eta$ is given by formula:

$$
\eta=\frac{3 \cos ^{2}\left(\beta_{r} / 2\right)}{3 \sin ^{2}\left(\beta_{r} / 2\right)-1}
$$

where $\beta_{r}$ is the reorientation angle of the $\mathrm{C}-\mathrm{H}$ bonds off the flip axis before and after the motion and is close to $120^{\circ}$.
Fast molecular motion can reduce the principal component of the dipolar tensor by factor $(S)$, which is called the order parameter. For powder patterns, the $S$ is in range from 0.5 to 1 . The latter value represents rigid systems. The order parameters related to dynamic models, including diffusion in a cone and the three-site hop for aliphatic groups as well two-site jumping or diffusion in a flattened cone typical for dynamics of phenyl rings were exhaustively discussed. ${ }^{26,27}$

Molecular dynamics of polycarbonate-powdered polymer at room temperature was investigated in detail by Schaeffer et al. as well as Hong et al. ${ }^{26,28} \mathrm{~A}$ complex motion involving $180^{\circ}$ ring flips superimposed with wobbling motions and distribution of amplitudes around the equilibrium positions was confirmed. For such kind of motion with a reorientation angle of $120^{\circ}$ and a wobbling amplitude distribution of $20^{\circ}$ splitting between singularities is equal to $6.6 \mathrm{kHz}$.

Figure 7 shows the 1D projections taken from PILGRIM correlations for PC film recorded at temperatures 296, 373, and 393 K. Similar Variable Temperature (VT) measurements were carried out for PS film, however since the glass transition for PS is in the range of 378-383 K, we have measured this sample at 296, 348, 373, and $388 \mathrm{~K}$ (middle column). The VT LG CP approach was also employed for $70: 30$ PC/PS film (right column).

From inspection of 1D spectra shown in Figure 7, the distinct molecular dynamics for pure polymers can be concluded. For PC film measured at $296 \mathrm{~K}$ the line shape of ${ }^{1} \mathrm{H}-{ }^{13} \mathrm{C}$ doublet and splitting between singularities is the same as those reported by Hong et $\mathrm{al}^{26}$ for powdered PC sample. With the increase of temperature the dip between singularities becomes smaller. It is very likely related to the increase of wobbling amplitude with temperature.

The lineshape of PS film (middle column) at 296 $\mathrm{K}$ is significantly different compared to PC. Molecular dynamics of phenyl ring for polystyrene was investigated in details employing various solid state NMR approaches. Spiess ${ }^{29,30}$ examined the $180^{\circ}$ ring flip transition in deuterated atactic PS glasses using ${ }^{2} \mathrm{H}-\mathrm{NMR}$ spectroscopy and concluded that $\sim 20 \%$ of the phenyl rings exhibit rapid $180^{\circ}$ flips about the ring axis defined by the carbon bond connecting the phenyl ring to the backbone of the polymer chain.

Schaeffer et al. ${ }^{31}$ studied phenyl ring rotation in PS glasses using ${ }^{13} \mathrm{C}$-NMR spectroscopy and interpreted their observations in terms of a concerted motion consisting of $180^{\circ}$ flips coupled with restricted main-chain reorientations. It was found that only $7 \%$ of the phenyl rings execute $180^{\circ}$ ring flips. It was further speculated that the cooperative 


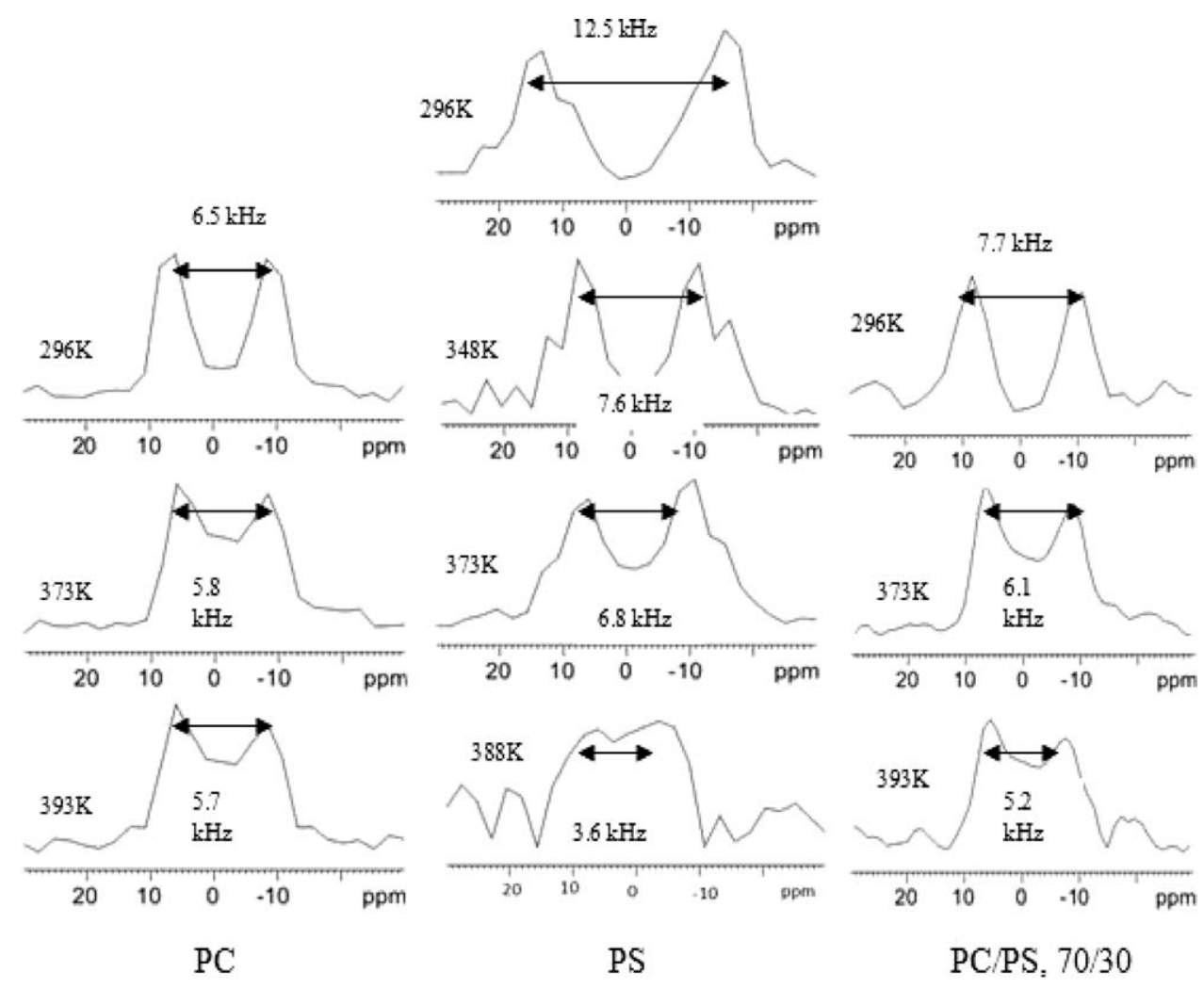

Figure 7 1D projections taken from PILGRIM correlations.

motion could only occur in those regions of the glass where chain packing results in high main-chain flexibility.

Our LG CP results clearly prove that at $296 \mathrm{~K}$ phenyl ring orientation in PS film is static. The splitting between singularities is $12.5 \mathrm{kHz}$, typical value for rigid aromatic systems. The few percents of mobile component (if exists in our sample) is not detected by PILGRIM experiment. At slightly higher temperature $(348 \mathrm{~K})$ the presence of two subspectra with splitting equal to 7.6 and $11.8 \mathrm{kHz}$ is apparent. The mobile component, undergoing fast molecular motion is dominating. At the temperature $388 \mathrm{~K}$, the phenyl rings are very mobile. Splitting between singularities for Pake doublet is very small.

Finally, we have searched for the influence of PS on dynamics of phenyl rings of PC for PC/PS film with ratio $70: 30$ in the temperature range from 296 to $393 \mathrm{~K}$ (right column). It is clear from our study that at $296 \mathrm{~K}$ the splitting for this film is slightly larger $(7.7 \mathrm{kHz})$ compared with $\mathrm{PC}$. At $373 \mathrm{~K}$ the splitting is $6.1 \mathrm{kHz}$ while at $393 \mathrm{~K}$ splitting is 5.2 $\mathrm{kHz}$. The latter value is smaller than in the case of pure PC film. It means that above the glass transition temperature of PS the PC component became more flexible.

\section{CONCLUSIONS}

The significant shifts of glass transition temperature were observed in multilayer film: for PS component toward higher temperature and for PC toward lower temperature. It is the effect of the influence of the other component of multilayer film: when PS layers are reaching their glass transition temperature, it is in contact with still rigid PC layers resulting in an increase of glass temperature of PS. During further heating when approaching the glass transition temperature of $\mathrm{PC}$, the $\mathrm{PC}$ layers are in contact with rubbery PS layers resulting in lowering of glass transition temperature of PC.

Our LG CP NMR spectra clearly proved that at room temperature phenyl ring orientation in PS film is rather random. The splitting between singularities is $12.5 \mathrm{kHz}$, which is a typical value for rigid aromatic systems. A mobile component was not detected by PILGRIM experiment. At $348 \mathrm{~K}$, the presence of two subspectra with different splitting is apparent. The mobile component, undergoing fast molecular motion is dominating. This effect is even better seen at a higher temperature. At the temperature around and above, the glass transition of the phenyl rings of PS are very mobile.

The influence of PS on dynamics of phenyl rings of PC for PC/PS film depends very much on the 
temperature or rather on the level of departure from its glassy state. It is clear from our study that the splitting between singularities in 1D spectra of PILGRIM decreases with the increase of the temperature. The value of splitting gets significantly smaller than in the case of pure PC film. It means that above the glass transition temperature of PS the PC component of a multilayer film, although still being in glassy state, becomes more flexible.

\section{REFERENCES}

1. Liu, R. Y. F.; Ranade, A. P.; Wang, H. P.; Bernal-Lara, T. E.; Hiltner, A.; Baer, E. Macromolecules 2005, 38, 10721.

2. Baer, E.; Hiltner, A.; Keith, H. D. Science 1987, 235, 1015.

3. Kerns, J.; Hsieh, A.; Hiltner, A.; Baer, E. J Appl Polym Sci 2000, 77, 1545.

4. Jin, Y.; Rogunova, M.; Hiltner, A.; Baer, E.; Nowacki, R.; Galeski, A.; Piorkowska, E. J Polym Sci Part B: Polym Phys 2004, 42,3380 .

5. Hong, M.; Yao, X.; Jakes, K.; Huster, D. J Phys Chem B 2002, 106, 7355.

6. Avolio, R.; Gentile, G.; Avella, M.; Capitani, D.; Errico, M. E. J Polym Sci Part A: Polym Chem 2010, 48, 5618.

7. Schmidt-Rohr, K.; Spiess, H. W. Multidimensional Solid-State NMR and Polymers; Academic Press: London, 1994.

8. Asakura, T.; Ando, I., Eds. Solid State NMR of Polymers; Elsevier Science B.V.: Amsterdam, 1998.

9. Komoroski, R. A., Ed. High Resolution NMR Spectroscopy of Synthetic Polymers in Bulk; VCH: Deerfield Beach, FL, 1986.

10. Lu, J.; Mirau, P. A.; Tonelli, A. E. Prog Polym Sci 2002, 357 and references cited therein.
11. Spiess, H. W. Macromolecules 2010, 43, 5479.

12. Brown, S. P.; Spiess, H. W. Chem Rev 2001, 101, 4125.

13. Ladizhansky, V. Solid State Nucl Magn 2009, 36, 119.

14. Wylie, B. J.; Rienstra, C. M. J Chem Phys 2008, 128.

15. Drobny, G. P.; Long, Jr.; Karlsson, T. Annu Rev Phys Chem 2003, 54, 531.

16. Cobo, M. F.; Malinakova, K.; Reichert, D.; Saalwachter, K.; Deazevedo, E. R. Phys Chem Chem Phys 2009, 11, 7036.

17. Ladizhansky, V.; Vega, S. J Chem Phys 2000, 112, 7158.

18. Ramamoorthy, A.; Wei, Y.; Lee, D. K. Ann Rep NMR Spectrosc 2004, 52, 1 and references cited therein.

19. Pan, S. J.; Hill, M. J.; Keller, A.; Hiltner, A.; Baer, E. J Polym Sci Part B: Polym Phys 1990, 28, 1105.

20. Mueller, C. D.; Nazarenko, S.; Ebeling, T.; Schuman, T. L.; Hiltner, A.; Baer, E. Polym Eng Sci 1997, 37, 355.

21. Bernal-Lara, T. E.; Ranade, A.; Hiltner, A.; Baer, E. Mechanical Properties of Polymers Based on Nanostructure, 1st ed.;Micheler, G. H., Balta-Callaja, F., Eds.; CRC press: Boca Raton, Florida, 2005; p 629.

22. Morcombe, C. R.; Zilm, K. W. J Magn Reson 2003, 162, 479.

23. Metz, G.; Wu, X.; Smith, S. O. J Magn Reson Ser A 1994, 110, 219.

24. Bennett, A. W.; Rienstra, C. M.; Auger, M.; Lakshmi, K. V.; Griffin, R. G. J Chem Phys 1995, 103, 6951.

25. Topspin, Version 2.1; Germany.

26. Hong, M.; Yao, X.; Jakes, K.; Huster, D. J Phys Chem B 2002, $106,7355$.

27. Lorieau, J.; McDermott, A. E. Magn Reson Chem 2006, 44, 334.

28. Schaeffer, J.; Stejskal, E. O.; Perchak, D.; Skolnick, J.; Yaris, R. Macromolecules 1985, 18, 368.

29. Spiess, H. W. Colloids Polym Sci 1983, 262, 193.

30. Spiess, H. W. J Mol Struct 1983, 111, 119.

31. Schaeffer, J.; Sefcik, M. D.; Stejskal, E. O.; McKay, E. A.; Dixon, W. T.; Cais, R. E. Macromolecules 1984, 17, 1107. 